\title{
AUTISMO: UMA AVALIAÇÃO TRANSDISCIPLINAR BASEADA NO PROGRAMA TEACCH
}

\section{Autism: a transdisciplinary approach based on TEACCH program}

\author{
Caroline Sianlian Kwee (1), Tania Maria Marinho Sampaio ${ }^{(2)}$, Ciríaco Cristóvão Tavares Atherino ${ }^{(3)}$
}

\begin{abstract}
RESUMO
Objetivo: apresentar protocolo de avaliação transdisciplinar no autismo baseado no programa denominado Treatment and Education of Autistic and related Communicattion handicapped Children TEACCH e sua aplicação no programa desenvolvido na Organização Não -Governamental Centro de Referência e Apoio às Desordens do Desenvolvimento - CRADD. Métodos: foram escolhidos seis indivíduos, entre sete e doze anos, com diagnóstico de autismo que frequentam o programa da referida e que foram avaliados em três momentos durante o ano (janeiro, junho e dezembro). Resultados: foram verificados os progressos de cada um deles nas áreas de interação social, comportamento, aspecto cognitivo e linguagem. Conclusão: independente do grau e do tipo de autismo, a aplicação da abordagem transdisciplinar nos sujeitos, demonstrou que existe desenvolvimento em todas as áreas avaliadas, proporcionando o efetivo estabelecimento das suas funções comunicativas.
\end{abstract}

DESCRITORES: Transtorno Autístico; Avaliação; Educação

\section{INTRODUÇÃO}

\section{Autismo}

A principal característica do Transtorno do Espectro Autista é o déficit considerável na interação social, no comportamento e, invariavelmente, na comunicação. Em sua maioria, com ausência de comunicação verbal e, quando presente, nos casos de Autismo Leve e na Síndrome de Asperger, as dificuldades se encontram principalmente no que se refere à pragmática, prejudicando ainda mais a interação social deste indivíduo ${ }^{1-3}$. O que mais chama a atenção é a complexidade dos sintomas e, ainda atual, a diversidade de explicações etiológicas,

(1) Fonoaudióloga; Diretora do Centro de Referência e Apoio às Desordens do Desenvolvimento, CRADD, Rio de Janeiro, RJ; Mestre em Fonoaudiologia pela Universidade Veiga de Almeida.

(2) Filósofa; Professora Doutora do Curso de Mestrado Profissionalizante de Fonoaudiologia da Universidade Veiga de Almeida, UVA, Rio de Janeiro, RJ; Doutora em Filosofia pela Universidade Gama Filho.

(3) Médico; Professor Doutor do Curso de Mestrado Profissionalizante de Fonoaudiologia da Universidade Veiga de Almeida, UVA, Rio de Janeiro, RJ; Doutor em Otorrinolaringologia pela Universidade de São Paulo.

Conflito de interesses: inexistente que tentam enquadrar o autismo nas mais distintas áreas do conhecimento, que resultam em diferentes e, por vezes, divergentes abordagens clínicas, terapêuticas e educacionais.

Autores concordam em citar o autismo como uma questão que apresenta grandes controvérsias, uma vez que engloba, dentro dos seus conceitos, uma gama bastante variada de doenças com diferentes quadros clínicos que têm como fator comum o autismo ${ }^{4,5}$. Colocam ainda o autismo como "objeto de controvérsias e frequentes alterações na sua descrição e categorização" 6 .

Nas teorias formuladas sobre o autismo, a linguagem é constantemente enfocada, sendo o profissional da fonoaudiologia, um dos primeiros procurados pelas famílias para diagnóstico e intervenção nos atrasos de linguagem das crianças. Assim o papel do fonoaudiólogo varia de acordo com a perspectiva teórica abordada e afeta diretamente a atuação terapêutica e sua prática educativa ${ }^{5}$.

Dentro da perspectiva do atendimento fonoaudiológico individual, a criança com autismo é estimulada a fazer uso da comunicação, desde a utilização de padrões articulatórios adequados, através do treino da fala (quando ela existe) até o uso da linguagem funcional da abordagem pragmática ${ }^{6}$. Porém, com a prática clínica dos últimos anos, observou-se que 
ainda existe uma lacuna no processo comunicativo dessas crianças, principalmente das não-verbais, evidenciadas nas dificuldades de comportamento e de interação social $4,7,8$.

Partindo do princípio de que a comunicação surge da interação, não é difícil imaginar porque a linguagem está bastante prejudicada no Transtorno do Espectro Autista, sendo quase uma consequência das dificuldades que esse indivíduo tem nas capacidades de interação social e comportamento. Tais dificuldades geram inúmeras alterações na forma de estabelecer contato com o mundo, criando em torno do indivíduo um universo repleto de estereotipias, ecolalias, comportamentos rotineiros e hiperativos, dificuldades graves de generalizações, reações inusitadas às mudanças de rotina, além de uma comunicação verbal e não-verbal sem contexto ${ }^{6,9-12}$.

É diante desse quadro que muitas vezes o fonoaudiólogo recebe uma criança com autismo. Com os recursos teóricos da Fonoaudiologia, requer-se estabelecer a fala bem como a comunicação com o sujeito. É com esta preocupação que quer se rever o atendimento clínico desconectado de outras necessidades de um sujeito tão peculiar e complexo, principalmente sendo ele a criança não-verbal ${ }^{13-16}$.

No caso da criança com Autismo, o modelo dos atendimentos multi ou interdisciplinares reforçam uma das principais características do transtorno, que é a dificuldade de generalização aumentando o tempo de investimento na criação dos vínculos com cada profissional, já que a criança com autismo possui graves problemas de interação.

\section{Transdisciplinaridade}

A cultura se refere a padrões compartilhados do comportamento humano. As normas culturais afetam a maneira com que as pessoas pensam, comem, se vestem, trabalham, compreendem os fenômenos naturais, usam o tempo de lazer, se comunicam, abrangendo tantos outros aspectos fundamentais das interações humanas ${ }^{17,18}$. As culturas apresentam ampla diversidade, de forma que as pessoas de uma cultura para outra podem lidar com a incompreensão ou até mesmo com estranheza. As pessoas pensam, sentem e se comportam de certa forma porque alguém as ensinou como se deve viver nesse mundo ${ }^{19}$. É a cultura sendo passada de uma geração para outra.

O autismo, obviamente, não é uma cultura; é um transtorno de desenvolvimento causado por uma disfunção neurológica. Entretanto, ele também afeta a maneira como as pessoas se alimentam, se vestem, usam seu tempo de lazer, entendem seu mundo e se comunicam. Consequentemente, de alguma forma, o autismo funciona como uma cul- tura, sob a perspectiva de que ele produz padrões de comportamento característicos e previsíveis nas pessoas sob esta condição ${ }^{8}$.

O papel do profissional que trabalha com autismo é semelhante ao de um intérprete ou guia transcultural: alguém que entende ambas as culturas e é capaz de traduzir e orientar as expectativas e procedimentos de um ambiente não-autístico para o indivíduo com alterações complexas e abrangentes.

Porém, com a extensão das dificuldades enfrentadas pelo indivíduo com Autismo, surgem, em nome da ciência, diferentes tipos de intérpretes. Observa-se a proliferação de distintas e concomitantes atuações dos profissionais envolvidos ${ }^{20}$. Deixa-se de olhar o indivíduo com autismo e passase a tratar do autismo. Repartem-se os saberes e instituíram-se graus de importância a cada área que apresenta comprometimento no indivíduo. Concorda-se aí com a complexidade da síndrome, mas deleta-se a complexidade do sujeito ${ }^{21}$.

A transdisciplinaridade, com olhar dirigido para complexidade, reside na possibilidade de ultrapassar o domínio das disciplinas formalmente estabelecidas, construindo uma teia de relações entre o saber da ciência, da arte, da política, e de tantos outros discursos humanos ${ }^{20}$ : aquilo que está ao mesmo tempo entre as disciplinas, através das diferentes disciplinas e além de qualquer disciplina. Seu objetivo é a compreensão do mundo presente, e para tal, é imprescindível a unidade do conhecimento ${ }^{21,22}$.

\section{O programa TEACCH}

O TEACCH, ou Tratamento e Educação para Autistas e Crianças com déficits relacionados à Comunicação, é um programa que envolve as esferas de atendimento educacional e clínico, em uma prática com abordagem psicoeducativa, tornando-o por definição, um programa transdisciplinar ${ }^{8}$.

Criado em 1966, na divisão de Psiquiatria da Escola de Medicina da Universidade da Carolina do Norte (EUA), por Eric Shopler e colaboradores, através de um projeto de pesquisa que procurou questionar a prática clínica daquela época, na sociedade americana, em que se acreditava que o Autismo tinha uma causa emocional e deveria ser tratado através dos princípios da psicanálise ${ }^{9}$.

Suas bases teóricas são a Teoria Behaviorista e a Psicolinguística. A valorização das descrições das condutas, a utilização de programas passo a passo e o uso de reforçadores, evidenciam as características comportamentais. Por outro lado, foi na psicolinguística que se buscou as estratégias para compensar os déficits comunicativos desta Síndrome, como a utilização de recursos visuais, 
proporcionando interação entre pensamento e linguagem e para ampliar as capacidades de compreensão, onde a imagem visual é geradora de comunicação. Assim, a teoria comportamental e a psicolinguística - bases epistemológicas do TEACCH - convergem para uma prática funcional e pragmática. Além disso, o entendimento da condição neurobiológica da Síndrome é fundamental neste modelo.

Os princípios cardeais do Programa são:

1. promover a adaptação de cada indivíduo de duas formas trans-atuantes: a primeira é melhorar todas as habilidades para o viver através das melhores técnicas educacionais disponíveis; a segunda, na medida em que existe um déficit envolvido, entender e aceitar esta deficiência, planejando estruturas ambientais que possam compensá-la;

2. colaboração mútua em nível de trabalho ativo onde os profissionais aprendem com os pais e usam suas experiências particulares relativas a seu próprio filho e, em contrapartida, os profissionais oferecem aos pais seu conhecimento na área e sua experiência. Juntos definem as prioridades dos programas, na Instituição, em casa e na comunidade. Esta união é politicamente a mais potente, tanto para o tratamento quanto para a pesquisa;

3. favorecer uma avaliação que permita a compreensão de quais são as habilidades atuais da criança, as habilidades emergentes e o que ajuda a desenvolvê-las. Os programas específicos de ensino e tratamento são individualizados e baseados em uma compreensão personalizada de cada indivíduo. A avaliação cuidadosa de cada um envolve tanto um processo de avaliação formal (os melhores e mais adequados testes disponíveis, quando possível), quanto informal (observações melhores e mais perspicazes dos pais, professores e outras pessoas em contato regular com a criança);

4. conhecer os sistemas teóricos, as teorias cognitivistas e behavioristas que guiam tanto a pesquisa quanto os procedimentos desenvolvidos pelo TEACCH;

5. atuar dentro de um modelo generalista e transdisciplinar, no qual os profissionais de qualquer disciplina interessados em trabalhar com esta população são capacitados como Generalistas. Isto significa que se espera que eles tenham uma habilidade funcional de lidar com toda a ampla gama de problemas provocados pelo autismo, independentemente de suas áreas de especialização. Isto permite que estes assumam a responsabilidade pelo indivíduo como um todo, assim como de consultar especialistas quando necessário, no entanto é à equipe que cabe a decisão.

A partir de então, apresenta-se o protocolo de avaliação transdisciplinar baseado do Programa
Treatment and Education of Autistic and related Communicattion handicapped Children - TEACCH, utilizado na instituição Não-Governamental Centro de Referência e Apoio às Desordens do Desenvolvimento - CRADD, a fim de observar o desenvolvimento e realizar os devidos ajustes nos programas de seis dos seus alunos.

Os dados levantados neste estudo devem iluminar novos caminhos para a Fonoaudiologia e condutas mais eficazes para o indivíduo portador de autismo.

\section{MÉTODOS}

Foram selecionados 6 (seis) indivíduos: RD. 7 anos, D. 7 anos, G. 8 anos, F, 10 anos, R. 11 anos e B. 12 anos, alunos do CRADD - Centro de Referência e Apoio às Desordens do Desenvolvimento, a partir de entrevista inicial para registro dos dados pessoais básicos e confirmação do diagnóstico de autismo, recebido pelo médico-neuropediatra que acompanha cada criança.

Não cabe a descrição das características individuais de cada sujeito neste trabalho, já que o objetivo em questão é a apresentação do protocolo avaliativo e não o estudo de caso de cada indivíduo estudado.

Os alunos frequentam a instituição, diariamente, por período mínimo de quatro horas e todos estão matriculados no programa desde janeiro de 2003. Não houve índice de absenteísmo considerável como variável e os responsáveis assinaram o termo de consentimento para a pesquisa.

Foram utilizados 4 (quatro) protocolos avaliativos e 1 (um) protocolo para os resultados, todas organizados pelos autores deste artigo.

Seguem, os protocolos avaliativos em ordem sequencial.

Figura 1 - Avaliação da Interação Social

Figura 2 - Avaliação das Funções Comunicativas

Figura 3 - Avaliação Cognitiva

Figura 4 - Avaliação do Comportamento

Os dados foram organizados em protocolos, numerados de 1 a 4 a partir das áreas comprometidas nos indivíduos com autismo: Interação social, com nove critérios; Funções comunicativas, com oito critérios; Aspectos cognitivos, com dez critérios e, Comportamento, com oito critérios. São observadas suas presenças ou ausências e foram convencionados os usos de palavras que determinam: Passou $(P)$, para o evento que o aluno realiza com independência e adequação, Emergente $(E)$, para o evento que o aluno demonstra conhecimento, mas não executa sozinho, Falhou $(F)$, para o evento que 
o aluno não executou mesmo após demonstração e repetição.

Para quantificar a evolução em cada área avaliada, foram convencionados números para as letras dos protocolos: Passou (P) -3 ; Emergente (E) - 2; Falhou $(F)-1$. Esse critério foi utilizado somente para demonstrar a existência de evolução nas áreas avaliadas.

Foram realizadas três avaliações com cada sujeito da amostra a fim de comparar os resultados intra-sujeitos. A primeira avaliação utilizando os protocolos propostos foi aplicada no início do ano letivo, no mês de janeiro. A segunda, no mês de junho e, a última, no mês de dezembro. Todas as avaliações utilizaram o mesmo protocolo e foram realizadas com um mediador (professora) e um observador (pesquisadora) que marca as respostas. Ocorreram dentro da sala de aula dos alunos, por ser um ambiente conhecido e tiveram duração de noventa minutos. As atividades propostas para as investigações dos itens foram as mesmas nas três avaliações. Como se trata de uma pesquisa de ordem qualitativa, não foram utilizados testes formais para as investigações dos critérios propostos. As atividades do programa psicoeducativo dos alunos e que foram avaliadas neste trabalho, fazem parte da sua rotina escolar diária.

A pesquisa foi aprovada pelo Comitê de Ética em Pesquisa sob o número 104/08.

\section{Protocolos Avaliativos}

\begin{tabular}{|c|c|}
\hline I) Interação Social & Observações \\
\hline Contato visual & $\begin{array}{l}\text { (P): Faz contato visual } \\
\text { (E): Faz contato visual ocasional } \\
\text { (F): Não faz contato visual }\end{array}$ \\
\hline Contato físico & $\begin{array}{l}\text { (P): Faz contato físico } \\
(\mathrm{E}): \text { Faz contato físico ocasional } \\
(\mathrm{F}): \text { Não faz contato físico }\end{array}$ \\
\hline Imitação & $\begin{array}{l}\text { (P): Faz imitação a partir de modelo gestual } \\
\text { (E): Faz imitação a partir de prompt físico } \\
\text { (F): Não faz imitação }\end{array}$ \\
\hline Repertório básico de conduta & $\begin{array}{l}\text { (P): Age segundo repertório básico de conduta } \\
\text { (E): Age segundo repertório básico de conduta com pistas } \\
(\mathrm{F}) \text { :Não age segundo repertório básico de conduta }\end{array}$ \\
\hline Reconhecimento do ambiente & $\begin{array}{l}\text { (P): Identifica os diferentes ambientes } \\
\text { (E): Identifica parcialmente os ambientes } \\
\text { (F): Não identifica os ambientes }\end{array}$ \\
\hline Atividades em grupo & $\begin{array}{l}\text { (P): Realiza atividades em grupo } \\
\text { (E): Realiza parcialmente atividades em grupo } \\
\text { (F): Não realiza atividades em grupo }\end{array}$ \\
\hline Relacionamento com terapeuta & $\begin{array}{l}\text { (P): Interage com o terapeuta } \\
(\mathrm{E}) \text { : Interage parcialmente com o terapeuta } \\
(\mathrm{F}) \text { : Não interage com o terapeuta }\end{array}$ \\
\hline $\begin{array}{l}\text { Relacionamento com os } \\
\text { colegas }\end{array}$ & $\begin{array}{l}\text { (P): Interage com os colegas } \\
(E) \text { : Interage parcialmente com os colegas } \\
(\mathrm{F}) \text { : Não interage com os colegas }\end{array}$ \\
\hline
\end{tabular}

Legenda: F: falhou; E: emergente; P: passou

Figura 1 - Avaliação da Interação Social 


\begin{tabular}{|l|l|}
\hline II) Comunicação & Observações \\
\hline \multirow{4}{*}{ Linguagem compreensiva } & (P): Atende às solicitações \\
& (E): Atende parcialmente às solicitações \\
& (F): Não atende às solicitações \\
\hline \multirow{5}{*}{ Linguagem gestual } & (P): Utiliza a linguagem gestual \\
& (E): Utiliza parcialmente a linguagem gestual \\
& (F): Não utiliza a linguagem gestual \\
\hline \multirow{2}{*}{ Compreensão das mudanças } & (P): Entende as mudanças prosódicas \\
& (E): Entende parcialmente as mudanças prosódicas \\
& (F): Não entende as mudanças prosódicas \\
\hline \multirow{5}{*}{ Linguagem social } & (P): Utiliza a linguagem social \\
& (E): Utiliza parcialmente a linguagem social \\
& (F): Não utiliza a linguagem social \\
\hline \multirow{5}{*}{ Ecolalia } & (P): Não fala de forma ecolálica \\
& (E): Fala parcialmente de forma ecolálica \\
& (F): Fala de forma ecolálica \\
\hline \multirow{5}{*}{ Linguagem expressiva } & (P): Utiliza a linguagem expressiva \\
& (E): Utiliza parcialmente a linguagem expressiva \\
& (F): Não utiliza a linguagem expressiva \\
\hline \multirow{5}{*}{ Linguagem escrita } & (P): Utiliza a linguagem escrita \\
& (E): Utiliza parcialmente a linguagem escrita \\
\hline \multirow{5}{*}{ Leitura } & (F): Não utiliza a linguagem escrita \\
\hline & (P): Lê \\
& (E): Lê parcialmente \\
& (F): Não lê \\
\hline
\end{tabular}

Legenda: F: falhou; E: emergente; P: passou

Figura 2 - Avaliação das Funções Comunicativas

\section{RESULTADOS}

Os resultados foram organizados em um único protocolo com uma coluna para os sujeitos e outra para os meses que ocorreram as avaliações (Figura 5). Dentro de cada célula, para cada sujeito, foram abreviadas as áreas avaliadas: IS - interação social, FC - funções comunicativas, AC - avaliação cognitiva e ACOMP - avaliação do comportamento, onde foram colocados os resultados numéricos obtidos através da marcação dos protocolos. Cabe aqui ressaltar que, para as letras usadas na marcação dos protocolos, foram convencionados os valores: $\mathrm{F}$ (falhou) - 1; E (emergente) - 2 e P (passou) - 3 .

Pode-se observar que ao longo do ano em que ocorreram as avaliações, todos os sujeitos envolvidos obtiveram crescimento positivo em todas as áreas avaliadas. A escolha pela apresentação dos resultados de cada sujeito, atende ao objetivo deste trabalho e ao propósito do protocolo, que visa estudar as relações intra-sujeitos e não compará-los entre si, respeitando suas características individuais. É possível, ainda, analisar quais as áreas onde o aluno apresenta maior potencialidade, favorecendo o direcionamento do seu programa.

\section{DISCUSSÃO}

A amostra utilizada nesta pesquisa permitiu a observação das condições bastante peculiares que cada indivíduo com autismo apresenta. Mesmo assim é possível perceber evolução positiva em cada um dos sujeitos estudados.

Pela razão dos problemas de base orgânica, determinantes do autismo, e estes não serem reversíveis ${ }^{5,9}$, não tomou-se a "normalidade" como meta de nossos esforços terapêuticos e educacionais, fato que se coloca frente às dificuldades de uma pesquisa quantitativa e comparativa.

Diferentemente, a meta em longo prazo do Programa TEACCH é que o aluno com autismo se adeque o melhor possível à nossa sociedade quando adulto ${ }^{5,8}$. Atinge-se esta meta através do respeito 


\begin{tabular}{|c|c|}
\hline III) Aspectos Cognitivos & Observações \\
\hline Atenção & $\begin{array}{l}\text { (P): Mantém a atenção no estímulo } \\
\text { (E): Mantém a atenção no estímulo com pistas } \\
\text { (F): Não mantém a atenção }\end{array}$ \\
\hline Interesses & $\begin{array}{l}\text { (P): Demonstra interesse por determinado estímulo } \\
\text { (E): Demonstra interesse por determinado estímulo com pistas } \\
\text { (F): Não demonstra interesse }\end{array}$ \\
\hline Pareamento & $\begin{array}{l}\text { (P): Pareia objetos } \\
(\mathrm{E}): \text { Pareia objetos com auxilio } \\
(\mathrm{F}) \text { : Não pareia objetos }\end{array}$ \\
\hline Discriminação visual & $\begin{array}{l}\text { (P): Discrimina visualmente objetos } \\
\text { (E): Discrimina visualmente objetos com pistas } \\
(\mathrm{F}) \text { : Não discrimina objetos visualmente }\end{array}$ \\
\hline Discriminação auditiva & $\begin{array}{l}\text { (P): Discrimina auditivamente sons } \\
\text { (E): Discrimina auditivamente sons com pistas } \\
\text { (F): Não discrimina sons auditivamente }\end{array}$ \\
\hline Classificação & $\begin{array}{l}\text { (P): Organiza objetos } \\
(\mathrm{E}) \text { : Organiza objetos com auxilio } \\
(\mathrm{F}) \text { : Não organiza objetos }\end{array}$ \\
\hline Figura-Fundo & $\begin{array}{l}\text { (P): Discrimina os planos visuais dos objetos } \\
\text { (E): Discrimina os planos visuais dos objetos com pistas } \\
(\mathrm{F}) \text { : Não discrimina os planos visuais dos objetos }\end{array}$ \\
\hline Associação de ideias & $\begin{array}{l}\text { (P): Relaciona idéias } \\
(E) \text { : Relaciona idéias com pistas } \\
(\mathrm{F}) \text { : Não relaciona idéias }\end{array}$ \\
\hline Memória visual & $\begin{array}{l}\text { (P): Retém estímulo visual } \\
\text { (E): Retém estímulo visual com pistas } \\
\text { (F): Não retém estímulo visual }\end{array}$ \\
\hline Memória auditiva & $\begin{array}{l}\text { (P): Retém estímulo auditivo } \\
\text { (E): Retém estímulo auditivo com pistas } \\
(\mathrm{F}) \text { : Não retém estímulo auditivo }\end{array}$ \\
\hline
\end{tabular}

Legenda: F: falhou; E: emergente; P: passou

Figura 3 - Avaliação Cognitiva

pelas diferenças que o autismo cria em cada aluno, e os trabalha inseridos na cultura dele, ou dela, para ensinar as habilidades necessárias para funcionarem, incluídos na sociedade. Os esforços são direcionados para expandir as habilidades e entender os alunos, enquanto adaptam-se os ambientes às suas necessidades especiais e limitações.

As explicações verbais são adequadas para a maioria das pessoas, para os indivíduos com autismo elas são frequentemente ineficazes, e ocasionalmente contraprodutiva. Esta afirmação é verdadeira, independentemente do nível cognitivo do indivíduo ${ }^{5,6}$. Mesmo pessoas (nesse caso, alunos) com extenso vocabulário expressivo podem ter uma habilidade muito limitada de atender ou processar a explicação verbal do terapeuta. Eles podem não saber quando se fala com eles, mesmo quando estão prestando atenção; tendem a não entender o conteúdo idiomático da linguagem, conotações sutis, inferências lógicas ou vocabulário complexo ${ }^{23}$. Os alunos que, além do autismo, são portadores de deficiência mental são ainda menos aptos a aprender efetivamente através de meios verbais. Isso é claramente comprovado pelas diferenças nos resultados dos dois alunos de sete anos, com diferentes resultados no critério funções comunicativas.

Isto quer dizer que os professores e terapeutas não devam usar linguagem verbal como uma modalidade de atendimento, mas que a dependência nesta modalidade isolada irá tender a ser improdutiva e frustrante, tanto para o profissional, quanto para o aluno. 


\begin{tabular}{|c|c|}
\hline IV) Comportamento & Atividades / Observações \\
\hline Estereotipias & $\begin{array}{l}\text { (P): Não apresenta estereotipias } \\
\text { (E): Apresenta estereotipias em determinadas situações } \\
\text { (F): Apresenta estereotipias }\end{array}$ \\
\hline Agressividade & $\begin{array}{l}\text { (P): Não apresenta agressividade } \\
\text { (E): Apresenta agressividade em determinadas situações } \\
\text { (F): Apresenta agressividade }\end{array}$ \\
\hline Passividade & $\begin{array}{l}\text { (P): Não apresenta passividade } \\
\text { (E): Apresenta passividade em determinadas situações } \\
\text { (F): Apresenta passividade }\end{array}$ \\
\hline Hiperatividade & $\begin{array}{l}\text { (P): Não tem comportamento hiperativo } \\
\text { (E): Apresenta comportamento hiperativo em determinadas } \\
\text { situações } \\
\text { (F): Apresenta comportamento hiperativo } \\
\end{array}$ \\
\hline Hipoatividade & $\begin{array}{l}\text { (P): Não tem comportamento hipoativo } \\
\text { (E): Apresenta comportamento hipoativo em determinadas situações } \\
\text { (F): Apresenta comportamento hipoativo }\end{array}$ \\
\hline Alimentação & $\begin{array}{l}\text { (P): Alimenta-se normalmente } \\
(\mathrm{E}) \text { : Aceita limite na obssessão/aceita apresentação na abstenção } \\
(\mathrm{F}) \text { : Alimenta-se obssessivamente/abstém-se }\end{array}$ \\
\hline Comportamento Sensorial & $\begin{array}{l}\text { (P): Tem percepção sensorial adequada } \\
\text { (E): Tem percepção sensorial adequada com auxílio } \\
\text { (F): Não tem percepção sensorial adequada }\end{array}$ \\
\hline Atividades da vida diária & $\begin{array}{l}\text { (P): Atua adequadamente na rotina diária } \\
(\mathrm{E}) \text { : Atua adequadamente na rotina diária com auxílio } \\
(\mathrm{F}) \text { : Não atua adequadamente na rotina diária }\end{array}$ \\
\hline
\end{tabular}

Legenda: F: falhou; E: emergente; P: passou

Figura 4 - Avaliação do Comportamento

$\mathrm{Na}$ sociedade, genericamente recompensa-se as aquisições dos alunos com respostas sociais, tais como um elogio, sorrisos, tapinhas nas costas, e outras ações que comunicam "Eu estou orgulhoso de você". Estes atos dependem da habilidade do aluno de decodificar os símbolos do prazer do professor / terapeuta, e da significação para o aluno do orgulho dele ${ }^{24}$. Mas, o aluno com autismo pode não entender a intenção comunicativa de um sorriso, tapinhas nas costas, de um abraço, etc. Ou ele pode não reconhecer a relevância e significação das expressões de satisfação do terapeuta.

Desta forma, para os alunos com autismo, o reforçamento social tem, frequentemente, uma efetividade limitada. Enquanto usualmente se oferece, tem que se acrescentar a eles, o uso de outros métodos que são mais significativos para esses alunos.

Para atingir estas metas e para ajudar pessoas com autismo a funcionar mais adaptados na cultura, é necessário conceber programas tendo como base os pontos fortes e déficits fundamentais do autismo, que afetam o aprendizado e as interações no diaa-dia ${ }^{25}$. Esta abordagem do autismo é relativa, mas diferente de identificar déficits com objetivos diagnósticos. As características diagnósticas do autismo, tais como déficits nas áreas social e problemas de comunicação, são úteis para distinguir o autismo de outras deficiências, mas são relativamente imprecisos para a conceituação de como um indivíduo com autismo entende o mundo, age com base nesta compreensão, e aprende.

Diante de tais dificuldades e da complexidade já demonstrada, observa-se que trabalhar com indivíduos com autismo requer do profissional, profundo conhecimento sobre as diferentes características autísticas, e como administrá-las a favor do trabaIho e do sujeito. Isso requer conhecimento em diferentes áreas bem como se apropriar de diferentes atuações terapêuticas e educativas ${ }^{21-26}$.

O olhar transdisciplinar sobre essa questão permite que o profissional, responsável pela atuação direta com o indivíduo com autismo, receba o maior 


\begin{tabular}{|c|c|c|c|c|c|c|}
\hline \multirow{5}{*}{ Sujeito RD } & \multicolumn{2}{|c|}{ JANEIRO } & \multicolumn{2}{|c|}{ JUNHO } & \multicolumn{2}{|c|}{ DEZEMBRO } \\
\hline & IS & 11 & IS & 12 & IS & 18 \\
\hline & FC & 10 & FC & 11 & $\mathrm{FC}$ & 13 \\
\hline & $A C$ & 14 & $A C$ & 19 & $A C$ & 24 \\
\hline & ACOMP & 13 & ACOMP & 14 & ACOMP & 14 \\
\hline \multirow{4}{*}{ Sujeito D } & IS & 13 & IS & 15 & IS & 20 \\
\hline & FC & 8 & $\mathrm{FC}$ & 11 & FC & 15 \\
\hline & $\mathrm{AC}$ & 17 & $A C$ & 21 & $\mathrm{AC}$ & 24 \\
\hline & ACOMP & 14 & ACOMP & 13 & ACOMP & 15 \\
\hline \multirow{4}{*}{ Sujeito G } & IS & 12 & IS & 12 & IS & 18 \\
\hline & $\mathrm{FC}$ & 10 & $\mathrm{FC}$ & 11 & FC & 15 \\
\hline & $\mathrm{AC}$ & 23 & $A C$ & 28 & $A C$ & 30 \\
\hline & ACOMP & 14 & ACOMP & 15 & ACOMP & 16 \\
\hline \multirow{4}{*}{ Sujeito F } & IS & 21 & IS & 25 & IS & 27 \\
\hline & FC & 14 & FC & 18 & FC & 24 \\
\hline & $\mathrm{AC}$ & 24 & $\mathrm{AC}$ & 27 & $\mathrm{AC}$ & 29 \\
\hline & ACOMP & 18 & ACOMP & 21 & ACOMP & 21 \\
\hline \multirow{4}{*}{ Sujeito R } & IS & 16 & IS & 17 & IS & 23 \\
\hline & FC & 14 & $\mathrm{FC}$ & 17 & $\mathrm{FC}$ & 18 \\
\hline & $A C$ & 24 & $A C$ & 28 & $\mathrm{AC}$ & 29 \\
\hline & ACOMP & 15 & ACOMP & 17 & ACOMP & 17 \\
\hline \multirow{4}{*}{ Sujeito B } & IS & 18 & IS & 19 & IS & 20 \\
\hline & FC & 12 & FC & 15 & $\mathrm{FC}$ & 18 \\
\hline & $A C$ & 26 & $A C$ & 26 & $A C$ & 26 \\
\hline & ACOMP & 17 & ACOMP & 17 & ACOMP & 17 \\
\hline
\end{tabular}

Legenda: IS - Interação Social; FC - Funções Comunicativas; AC - Avaliação Cognitiva; ACOMP - Avaliação do Comportamento

Figura 5 - Tabela de Resultados

número de informações das diferentes áreas que compõem o protocolo e possa, junto com a equipe transdisciplinar, organizar as estratégias de abordagens psicoeducativas do programa TEACCH ${ }^{27}$. A possibilidade de redirecionar o olhar do terapeuta generaliza e amplia seus conceitos sobre o aluno com autismo e, consequentemente, também estende as possibilidades do desenvolvimento destes. As parcerias formadas entre as diferentes especialidades, torna a equipe coesa e fundamenta os objetivos no trabalho com os alunos. Apesar das formações e características distintas de cada membro da equipe, o foco de atuação é comum e compartilhado com todas as pessoas da instituição, inclusive com os pais. Os resultados obtidos, aparentemente discretos, refletem a uniformidade do trabalho: todas as áreas investigadas sofreram alterações, que levam a um benefício generalizado e não setorizado, ao indivíduo com autismo.

\section{CONCLUSÃO}

A individualização é um conceito chave nos programas educacionais baseados no TEACCH. Apesar das características do autismo que eles têm em comum, os alunos são extremamente diferentes uns dos outros, em termos de competências, áreas de dificuldade e idiossincrasias.

Com base nos resultados obtidos através do protocolo avaliativo proposto, observou-se que todos os alunos do programa obtiveram evolução positiva em todas as áreas e que apesar da complexidade das suas estruturas, os ganhos e as manutenções dos comportamentos adquiridos foram conquistados e estabilizados.

Os protocolos avaliativos baseados no programa TEACCH auxiliam a equipe transdisciplinar a monitorar o programa individual dos alunos, permitindo discussões das diferentes especialidades, reunidas 
com o propósito de abranger o maior número de áreas a serem trabalhadas. As reuniões mensais de avaliação dos programas, realizadas nessa instituição, enriquecem o conhecimento de cada membro da equipe e fortalece o sentido do trabalho transdisciplinar.

Conclui-se que o trabalho terapêutico de pessoas com autismo é o de ver o mundo através de seus olhos, e usar esta perspectiva para ensiná-las a funcionarem inseridas na cultura de forma mais independente possível. Enquanto não se podem curar os déficits cognitivos subjacentes ao autismo, é pelo seu entendimento que planejamos programas educacionais efetivos na função de vencer o desafio deste transtorno do desenvolvimento tão singular.

\begin{abstract}
Purpose: to submit a transdisciplinary approach for evaluating autistic disorders. It was based on the program referred to as Treatment and Education of Autistic and related Communication handicapped Children - TEACCH and its application in children pertaining to Non-Governmental Organization Centro de Referência e Apoio às Desordens do Desenvolvimento - CRADD. Methods: six subjects who belong to the education program of the aforementioned institution, all with a positive autism diagnostic, ages between seven and twelve year old, were evaluated in three distinctive instances along the year (January, June and December). Results: the progress of each one in the areas of social interaction, behavior, cognitive aspects and language had been verified. Conclusion: one concluded that there were improvements in all investigated areas with no relationship to the degree or type of autistic disorder. Providing the effective recovery of their communicative functions.
\end{abstract}

KEYWORDS: Autistic Disorder; Evaluation; Education

\section{REFERÊNCIAS}

1. Carvalheira G, Vergani N, Brunoni D. Genética do autismo. Rev Bras Psiquiatr. 2004; 26(4):270-1.

2. Frith U, Happe F. Autism spectrum disorder. Curr Biol J. 2005; 15(19):R786-90.

3. Sthamer AC, Collings NM, Palinkas LA. Early intervention practices for children with autism: descriptions from community providers. Focus Autism Other Dev Disab. 2005; 20(2):66-79.

4. Frith C, Frith U. Theory of mind. Curr Biol J. 2005; 15(17):R644-6

5. Sperry LA, Mesibov GB. Perceptions of social challenges of adults with autism spectrum disorder. Autism Int J Res Prac. 2005; 9(4):362-76.

6. Fernandes FDM. Terapia de linguagem com crianças do espectro autístico: um estudo transversal. J Bras Fonoaudiol. 2003 jun; 8(1): 25-36.

7. Dichter GS, Belger A. Social stimuli interfere with cognitive control in autism. Neuroimage. 2007 apr; 35(3):1219-30.

8. Mesibov G. Formal and informal measures on the effectiveness of the TEACCH Programme. Autism Int J Res Prac. 2007; 1(1):25-35.
9. Probst P, Leppert T. Brief report: outcomes of a teacher training program for autism spectrum disorders. J Autism Dev Dis. 2008; 38(9):1791-6.

10. Frith $C D$, Frith U. Social cognition in humans. Curr Biol J. 2007; 17(16):R724-32.

11. Williams DL, Goldstein G, Minshew NJ. Neuropsychologic functioning in children with autism: further evidence for disordered complex information-processing. Child Neuropsychol. 2006 aug; $12(4-5): 279-98$.

12. Mesibov GB. A tribute to Eric Schopler. J Autism Dev Disord. 2006; 36(8):967-70

13. Mesibov GB, Fuentes J, Prior M, Wing L. The past decade. Autism Int J Res Prac. 2006; 10(1): 7-10.

14. Mesibov GB. Program for child with autism. J Autism Dev Disord. 2004; 34(3):363.

15. Bishop DV, Norbury CF. Executive functions in children with communications impairments, in relation to autistic symptomatology. I: Generativity. Autism Int J Res Prac. 2005; 9(1):7-27.

16. Bishop DV. Forty years on: Uta Frith's contribution to research on autism and dyslexia, 1966-2006. Quarterl J Exp Psychol. 2008; 61(1):16-26.

17. Domingues I. Oliveira AG, Silva EMP, Capuzzo H, Beirão PSL. Educação em revista. Rev Faculdade de Educação/UFMG. 1999 jun; 1(29):109-16. 
18. Oliveira AG, Barreto FCS, Capuzzo Filho $\mathrm{H}$, Domingues I, Beirão PSL, Barbosa RANM, et al. Preparando o futuro: educação, ciência e tecnologia - suas implicações para a formação da cidadania. Rev Bras Estud Pedag. 2000; 81(198):316-41.

19. Santos SS. Pesquisa em enfermagem sob o foco do conceito de complexidade de Edgar Morin. Rev Bras Enf. 2003; 56(6):687-9.

20. Paviani J. Seminário Internacional Interdisciplinaridade, Humanismo. Faculdade de Letras, Universidade do Porto; 2003. Disponível em: URL: $<\mathrm{http} / / \mathrm{www}$.humanismolatino.online.pt> Acesso em 12 fev 2006.

21. Morin E. Os sete saberes necessários para a educação do futuro. São Paulo: Cortez; 2005.

22. Nicolescu B. A lógica quântica e a transdisciplinaridade, IHU On-Line, Universidade do Vale do Rio dos Sinos, $n^{\circ} 122,8$ novembro 2004, pp. 7-11
23. Hirschfeld L, Bartmess E, White S, Frith U. Can autistic children predict behavior by social stereotypes? Curr Biol. 2007; 17(12):R451-2.

24. Rogers J, Viding E, Blair RJ, Frith U, Happé F. Autism spectrum disorder and psychopathy: shared cognitive underpinnings or double hit? Psychol Med. 2006; 36(12):1789-98

25. Happe F, Frith U. The weak coherence account: detail-focused cognitive style in autism spectrum disorders. J Autism Dev Disord. 2006; 36(1):5-25.

26. Iribarry IN. O diagnóstico transdisciplinar em psicopatologia. Rev Latinoam Psicopatol Fundam. 2003; 6(1):53-75.

27. Hamilton A, Brindley RM, Frith U. Imitation and action understanding in autistic spectrum disorders: how valid is the hypothesis of a deficit in the mirror neuron system? Neuropsychol. 2007; 45(8): 1859-68.

RECEBIDO EM: 02/04/2008

ACEITO EM: 12/03/2009

Endereço para correspondência:

Caroline Sianlian Kwee

Rua Álvaro Ramos 59, sala 101

Rio de Janeiro - RJ

CEP: 22280-110

E-mail: carolkwee@uol.com.br cradd@cradd.org.br 